\title{
Synthesis and antioxidant evaluation of novel indole-3-acetic acid analogues
}

\author{
Nagaraja Naik*, Honnaiah Vijay Kumar and Salakatte Thammaiah Harini \\ Department of Studies in Chemistry, University of Mysore, Manasagangotri, Mysore-570006, Karnataka, India \\ ${ }^{*}$ Corresponding author at: Department of Studies in Chemistry, University of Mysore, Manasagangotri, Mysore-570006, Karnataka, India. Tel.: +91.948.2959088; \\ fax:+91.821.2419301. E-mail address: drnaik_chem@yahoo.co.in (N. Naik).
}

\section{ARTICLE INFORMATION}

Received: 05 December 2010

Received in revised form: 08 March 2011

Accepted: 14 March 2011

Online: 30 September 2011

\section{KEYWORDS}

Indole-3-acetic acid

Reactive oxygen species (ROS)

2-(1H-indol-3-yl)acetyl chloride

Antioxidant activity

Lipid peroxidation

Butylated hydroxy anisole (BHA)

\begin{abstract}
Indole-3-acetic acid (1) on reaction with thionyl chloride, afforded 2-(1H-indol-3-yl)acetyl chloride (2), which was further treated with aniline and various substituted anilines through base condensation reaction to obtain respected indole-3-acetic acid derivatives (3-9). The structures of all new compounds were elucidated by elemental analysis, Mass, IR, ${ }^{1} \mathrm{H}$ NMR and ${ }^{13} \mathrm{C}$ NMR and spectroscopic techniques. All the compounds were screened for their antioxidant activities by applying in vitro methods like 2,2-diphenyl-1-picryl hydrazyl (DPPH) free radical scavenging assay and inhibition of microsomal lipid peroxidation (LPO) assay. Butylated hydroxy anisole (BHA) was used as a reference antioxidant compound and the comparative study with newly synthesized compounds was also done. Among the analogues, compound 9 bearing electron donating methoxy substituent in addition to the phenolic moiety showed predominant activity. It is conceivable from these studies that the coupling of aniline and substituted anilines is the most important feature for the significant antioxidant activity of indole-3-acetic acid analogues studied.
\end{abstract}

\section{Introduction}

There is abundant evidence that reactive oxygen and nitrogen species (ROS and RNS) are implicated in several physiological processes, such as in host defense against invading pathogens and signal transduction [1,2]. An overproduction of such reactive species, however, plays a major role in several pathophysiological conditions, such as atherosclerosis, cardiovascular diseases, Parkinson and Alzheimer diseases, and some types of cancer [3-7]. To counterbalance such undesirable effects, the demand for natural and synthetic antioxidants to strengthen the endogenous defenses has grown in recent years.

Antioxidants must react with radicals and other reactive species faster than biological substrates, thus protecting biological targets from oxidative damage [8,9]. Furthermore, the resulting antioxidant radical must possess a high stability, that is, the antioxidant radical must interrupt (rather than propagate) a chain reaction [10]. The research on free radicals provides theoretical information for the medicinal development and supplies some in vitro methods for quickoptimizing drugs; it attracts more scientific attention for bioorganic and medicinal chemists. In addition to the traditional $\mathrm{O}-\mathrm{H}$ bond type antioxidants, aromatic amines having $\mathrm{N}-\mathrm{H}$ bond functions as the antioxidant have attracted much attention, because aromatic amines $\left(\mathrm{Ar}_{2} \mathrm{NHs}\right)$ have always been the central structure in many currently used drugs [11]. From the literature, phenolic compounds and some of the aromatic amines (heterocyclic amines) showed antioxidant properties in vitro and have been discussed from the view of chemical kinetics [12,13].

In the past decades research on synthesis and biological properties of indole-3-acetic acid has been actively pursued all over the world $[14,15]$ and there is lot of scope and ample opportunity to look for new antioxidant molecules. Keeping this in our mind, in the present investigation, we have taken one of the heterocyclic aromatic compound i.e. indole-3-acetic acid as a model compound. Even though many biological studies have been carried out on indole-3-acetic acid analogues [16-20], the antioxidant activities on same indole-3-acetic acid analogues bearing substituted aniline moieties were not been done.

Recently, we have reported the antioxidant properties of $5 \mathrm{H}$-dibenz[b,f]azepine, a tricyclic amine and some of its analogues, and their structure-activity relationships was established based on the different substituent's and positions [21-23]. Herein, we have reported the synthesis of indole-3acetic acid analogues obtained by coupling of aniline and different functionalized anilines. Antioxidant properties of indole-3-acetic acid and its analogues were evaluated using two well establishedwell-established in vitro models like DPPH radical scavenging assay and Inhibition of microsomal lipid peroxidation (LPO) assay.

\section{Experimental}

\subsection{Instrumentation}

Melting points were determined by open capillary method and were uncorrected. The IR spectra were recorded on a FTIR021 model in $\mathrm{KBr}$ disc. The ${ }^{1} \mathrm{H}$ and ${ }^{13} \mathrm{C}$ NMR spectra were recorded on Jeol GSX $400 \mathrm{MHz}$ spectrophotometer using $\mathrm{CDCl}_{3}$ as a solvent and the chemical shift $(\delta)$ are in ppm relative to internal standard. The Mass spectra were recorded on WatersQ-TOF Ultima spectrometer. Elemental analyses were obtained on a Carlo Erba analyzer. 


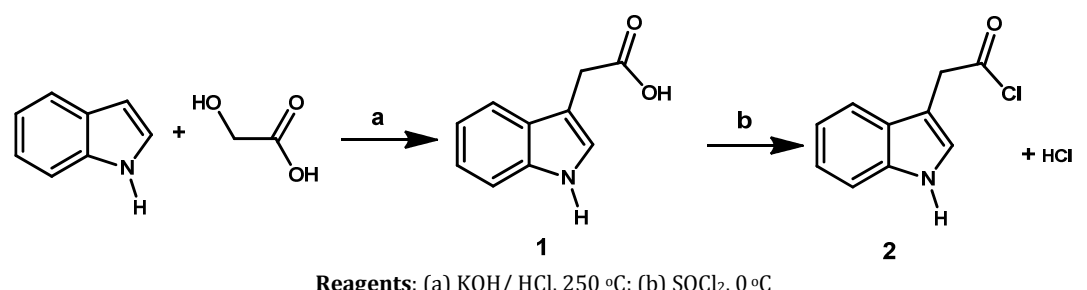

Reagents: (a) $\mathrm{KOH} / \mathrm{HCl}, 250{ }^{\circ} \mathrm{C}$; (b) $\mathrm{SOCl}_{2}, 0^{\circ} \mathrm{C}$

Scheme 1

\subsection{Chemicals}

DPPH was purchased from Sigma Aldrich, thionyl chloride, ethyl acetate, $n$-hexane, tetrahydrofuron, anhydrous potassium carbonate, methanol, chloroform, anhydrous sodium sulphate, aniline and substituted aniline like 2-hydroxyaniline, 3-hydroxyaniline, 4-hydroxyaniline, 4-hydroxy-3nitroaniline, 4-bromo aniline, 4-hydroxy-3-methoxy aniline, were all of analytical grade and procured from Merck . TLC aluminium sheets, silica-gel60 $\mathrm{F}_{254}$ was also purchased from Merck.

\subsection{Synthesis}

\subsubsection{Synthesis of 2(1H-indole-3-yl) acetyl chloride (2)}

To the well stirred solution of indole-3-acetic acid (2 mM) in $25 \mathrm{~mL}$ THF, thionyl chloride $(2.2 \mathrm{mM})$ in $25 \mathrm{~mL}$ THF was added drop by drop for about $15 \mathrm{~min}$. Then the reaction mixture was stirred at $30{ }^{\circ} \mathrm{C}$ temperature for about $6 \mathrm{hrs}$. Progress of the reaction was monitored by TLC using 2:8 methanol:chloroform mixture as mobile phase. Finally the reaction mixture was concentrated in rotary evaporated at 60 ${ }^{\circ} \mathrm{C}$, a brown solid product was obtained (Scheme 1). Brown solid. Yield: $84 \%$. M.p.: $115-117{ }^{\circ} \mathrm{C}$. FT-IR $\left(\mathrm{KBr}, \mathrm{cm}^{-1}\right)$ : 2913$3051(\mathrm{Ar}-\mathrm{H}), 3385(\mathrm{NH}), 1700(\mathrm{C}=0) .{ }^{1} \mathrm{H}$ NMR $\left(400 \mathrm{MHz}, \mathrm{CDCl}_{3}\right.$, $\delta$ ): 7.0-7.5 (m, $4 \mathrm{H}, \mathrm{Ar}-\mathrm{H}), 2.3-2.5\left(\mathrm{~d}, 2 \mathrm{H}, \mathrm{CH}_{2}\right), 4.2(\mathrm{~s}, 1 \mathrm{H}, \mathrm{NH}$ of indole), $4.2\left(\mathrm{~d}, 1 \mathrm{H}, \mathrm{CH}\right.$ of indole). ${ }^{33} \mathrm{C}$ NMR $\left(100 \mathrm{MHz}, \mathrm{CDCl}_{3}, \delta\right)$ : 118.6 (1C, Ar-C), 119.9 (1C, Ar-C), 121.4 (1C, Ar-C), 111.4 (1C, $\mathrm{Ar}-\mathrm{C}$ ), 136.8 (1C, $\mathrm{Ar}-C$ ), 127.1 (1C, $\mathrm{Ar}-C$ ), 109.1 (1C, Indole- $C$ ), 123.2 (1C, indole $-\mathrm{CH}$ ), 46.1 (1C, $\left.\mathrm{CH}_{2} \mathrm{COCl}\right), 172.8$ (1C, $\left.\mathrm{COCl}\right)$. MS (EI, m/z(\%): $193.10\left(\mathrm{M}+\right.$ ). Anal. Calcd. for $\mathrm{C}_{10} \mathrm{H}_{8} \mathrm{ClNO}$ : C, 62.03; $\mathrm{H}, 4.16$; Cl, 18.31; N, 7.23; 0, 8.26. Found: C, 62.00; H, 4.15; Cl, 18.32; N, 7.22.9; $0,8.24 \%$.

2.3.2. General procedure for the synthesis of 2-(1H-indol-3yl) acetyl chloride conjugated with different aniline and substituted anilines (3-9)

Aniline $(1.2 \mathrm{mM})$ in THF $(25 \mathrm{~mL})$ treated with anhydrous $\mathrm{K}_{2} \mathrm{CO}_{3}(100 \mathrm{mg})$. Later the solution of $2(1 \mathrm{H}$-indole-3-yl)acetyl chloride $2(1 \mathrm{mM})$ in THF $(25 \mathrm{~mL})$ was added drop by drop for 15 min under nitrogen atmosphere. The reaction mixture was refluxed for 6-8 hr. The progress of the reaction mixture was monitored by TLC using ethylacetate:hexane (6:4) as mobile phase. The reaction mixture was then desolventized in rotary evaporator and the compound was extracted in ethyl acetate. The organic layer was then washed with water and dried over anhydrous $\mathrm{Na}_{2} \mathrm{SO}_{4}$. The brown semisolid was obtained by further desolventation in rotary evaporator at $70{ }^{\circ} \mathrm{C}$. Other respective indole-3-acetic acid analogues were obtained by conjugated with substituted anilines like 2-hydroxyaniline, 3-hydroxyaniline, 4-hydroxyaniline, 4-hydroxy-3-nitro aniline, 4-bromo aniline, 4-hydroxy-3-methoxy aniline by following the same procedure. The analogues were separated and purified by column chromatography by using mixture of ethyl acetate: hexane 60:40. The products were characterized by IR, ${ }^{1} \mathrm{H}$ NMR, ${ }^{13} \mathrm{C}$ NMR and elemental analysis (Scheme 2).
2-(1H-indol-3-yl)-N-phenylacetamide (3): Brown semisolid. Yield: 87\%. FT-IR $\left(\mathrm{KBr}, \mathrm{cm}^{-1}\right)$ : 3035-2598 (Ar-H), $3233(\mathrm{NH}$ of indole), $1718(\mathrm{C}=0), 3376$ ( $\mathrm{NH}$ of aniline). ${ }^{1} \mathrm{H}$ NMR $(400 \mathrm{MHz}$, $\left.\mathrm{CDCl}_{3}, \delta, \mathrm{ppm}\right): 7.0-7.2(\mathrm{~m}, 4 \mathrm{H}, \mathrm{Ar}-\mathrm{H}), 2.2-2.6\left(\mathrm{~d}, 2 \mathrm{H}, \mathrm{CH}_{2}\right), 4.6(\mathrm{~s}$, $1 \mathrm{H}, \mathrm{N} H$ of indole), $3.8(\mathrm{~d}, 1 \mathrm{H}$, indole $\mathrm{C} H), 9.7(\mathrm{~s}, 1 \mathrm{H}, \mathrm{N}-H) ; 6.8-$ $7.3\left(\mathrm{~m}, 5 \mathrm{H}, \mathrm{Ar}-\mathrm{H}\right.$ of aniline). ${ }^{13} \mathrm{C}$ NMR $\left(100 \mathrm{MHz}, \mathrm{CDCl}_{3}, \delta, \mathrm{ppm}\right):$ 121.4 (1C, Ar-C), 128.2 (1C, Ar-C), 128.4 (1C Ar-C), 128.5 (1C, $\operatorname{Ar}-C$ ), 121.3 (1C, $\mathrm{Ar}-\mathrm{C}$ ), 138.2 (1C, Ar-C), 168.8 (1C, CO), 33.9 $\left(1 \mathrm{C}, \mathrm{NHCOCH}_{2}\right), 109.4$ (1C, Indole- $C$ ), 123.2 (1C, Indole- $C$ ), 127.1 (1C, Indole- $C$ ), 118.9 (1C, Indole- $C$ ), 119.5 (1C, Indole- $C$ ), 121.5 (1C, Indole- $C$ ), 111.0 (1C, Indole- $C$ ), 136.4 (1C, Indole- $C$ ). MS (EI, m/z(\%): $250.21(\mathrm{M}+)$. Anal. Calcd. for $\mathrm{C}_{16} \mathrm{H}_{14} \mathrm{~N}_{2} \mathrm{O}$ : C, 76.78; H, 5.64; N, 11.19; O, 6.39. Found: C, 76.76; H, 5.62; N, $11.18 ; 0,6.37 \%$.

N-(2-hydroxyphenyl)-2-(1H-indol-3-yl)acetamide (4): Brown semisolid. Yield: $83 \%$. FT-IR ( $\left.\mathrm{KBr}, \mathrm{cm}^{-1}\right)$ : 2827-3049 (Ar-H), 3210 ( $\mathrm{NH}$ of indole), 3296-3364 (phenolic-OH), 1710 (C=0), 3375 ( $\mathrm{NH}$ of substituted aniline). ${ }^{1} \mathrm{H}$ NMR $\left(400 \mathrm{MHz}, \mathrm{CDCl}_{3}, \delta\right.$, ppm): 7.4-7.0 (m, 4H, Ar- $H$ ), 2.3-2.6 (d, $\left.2 \mathrm{H}, \mathrm{CH}_{2}\right), 4.4(\mathrm{~s}, 1 \mathrm{H}, \mathrm{NH}$ of indole), $3.9(\mathrm{~d}, 1 \mathrm{H}$, indole $\mathrm{CH}), 9.4(\mathrm{~s}, 1 \mathrm{H}, \mathrm{N}-\mathrm{H}), 10.1(\mathrm{~s}, 1 \mathrm{H}$, phenolic $-\mathrm{OH}$ of substituted aniline), 6.7-7.2 (m, $4 \mathrm{H}, \mathrm{Ar}-\mathrm{H}$ of substituted aniline). ${ }^{13} \mathrm{C}$ NMR (100 $\left.\mathrm{MHz}, \mathrm{CDCl}_{3}, \delta, \mathrm{ppm}\right): 126.2$ (1C, $\mathrm{Ar}-C$ ), 148.5 (1C, Ar-C), 116.3 (1C, Ar-C), 125.8 (1C, Ar-C) 121.8 (1C, Ar-C), 120.5 (1C, Ar-C), 33.7 (1C, $\mathrm{NHCOCH}_{2}$ ), 168.6 (1C, CO), 118.5 (1C, Indole-C), 119.7 (1C, Indole-C), 121.9 (1C, Indole- $C$ ), 111.1 ( $1 \mathrm{C}$, Indole- $C$ ), 136.4 (1C Indole- $C$ ), 127.1 (1C, Indole- $C$ ), 109.1 (1C, Indole- $C$ ), 123.3 (1C, Indole- $C$ ). MS (EI, m/z(\%): $266.02(\mathrm{M}+)$. Anal. Calcd. for $\mathrm{C}_{16} \mathrm{H}_{14} \mathrm{~N}_{2} \mathrm{O}_{2}$ : C, 72.16; $\mathrm{H}$, 5.30; N, 10.52; 0, 12.02. Found: C, 72.14; H, 5.28; N, 10.51; O, $12.00 \%$.

N-(3-hydroxyphenyl)-2-(1H-indol-3-yl)acetamide (5): Brown semisolid. Yield: $81 \%$. FT-IR ( $\left.\mathrm{KBr}, \mathrm{cm}^{-1}\right)$ : 3046-2824 (Ar-H), 3310 (NH of indole), 3201-3360 (phenolic -OH), 1660 (C=0), 3200 ( $\mathrm{NH}$ of substituted aniline). ${ }^{1} \mathrm{H}$ NMR $\left(400 \mathrm{MHz}, \mathrm{CDCl}_{3}, \delta\right.$, ppm): 7.3-7.6 (m, 4H, Ar- $H$ ), 2.1-2.5 (d, 2H, CH$), 4.9(\mathrm{~s}, 1 \mathrm{H}, \mathrm{N} H)$, $4.0(\mathrm{~d}, 1 \mathrm{H}$, indole $\mathrm{C} H), 9.9(\mathrm{~s}, 1 \mathrm{H}, \mathrm{N}-H), 9.4(\mathrm{~s}, 1 \mathrm{H}$, phenolic $-\mathrm{OH}$ of substituted aniline), 6.7-7.2 (m, $4 \mathrm{H}, \mathrm{Ar}-\mathrm{H}$ of substituted aniline). ${ }^{13} \mathrm{C}$ NMR $\left(100 \mathrm{MHz}, \mathrm{CDCl}_{3}, \delta, \mathrm{ppm}\right): 139.7$ (1C, $\mathrm{Ar}-\mathrm{C}$ ), 105.4 (1C, Ar-C), 158.8 (1C, Ar-C), 114.8 (1C, Ar-C), 130.2 (1C, $\mathrm{Ar}-\mathrm{C}$ ), 109.5 (1C, Ar-C), 33.5 (1C, $\left.\mathrm{NHCOCH}_{2}\right), 168.7(1 \mathrm{C}, \mathrm{CO})$, 118.5 (1C, Indole- $C$ ), 119.6 (1C, Indole- $C$ ), 121.5 (1C, Indole- $C$ ), 111.0 ( $1 \mathrm{C}$, Indole- $C$ ), 136.1 ( $1 \mathrm{C}$, Indole- $C$ ), 127.2 (1C, Indole- $C$ ), 109.5 (1C, Indole-C), 123.2 (1C, Indole-C). MS (EI, m/z(\%): $266.12(\mathrm{M}+)$. Anal. Calcd. for $\mathrm{C}_{16} \mathrm{H}_{14} \mathrm{~N}_{2} \mathrm{O}_{2}$ : $\mathrm{C}, 72.16 ; \mathrm{H}, 5.30 ; \mathrm{N}$, 10.52; 0, 12.02. Found: C, 72.15; H, 5.28; N, 10.50; 0, 12.00\%.

N-(4-hydroxyphenyl)-2-(1H-indol-3-yl)acetamide (6): Brown semisolid. Yield: 84\%. FT-IR ( $\left.\mathrm{KBr}, \mathrm{cm}^{-1}\right)$ : 3042-2828 (Ar-H), $3336(\mathrm{NH}$ of indole), 3210-3360 (phenolic $\mathrm{OH}), 1701(\mathrm{C}=0)$, 3256 ( $\mathrm{NH}$ of substituted aniline). ${ }^{1} \mathrm{H}$ NMR $\left(400 \mathrm{MHz}, \mathrm{CDCl}_{3}, \delta\right.$, ppm): 7.3-7.0 (m, 4H, Ar- $H$ ), 2.4-2.6 (d, $2 \mathrm{H}, \mathrm{CH}_{2}, 4.8(\mathrm{~s}, 1 \mathrm{H}, \mathrm{N} H)$, $4.5(\mathrm{~d}, 1 \mathrm{H}$, indole $\mathrm{CH}), 9.3(\mathrm{~s}, 1 \mathrm{H}, \mathrm{N}-\mathrm{H}),, 9.8(\mathrm{~s}, 1 \mathrm{H}$, phenolic $\mathrm{OH})$, 6.9-7.4 (m, 4H, Ar- $H$ of substituted aniline). ${ }^{13} \mathrm{C}$ NMR (100 MHz, $\mathrm{CDCl}_{3}, \delta, \mathrm{ppm}$ ): 131.0 (1C, Ar-C), 123.2 (1C, $\mathrm{Ar}-\mathrm{C}$ ), 116.4 (1C, $\mathrm{Ar}-\mathrm{C}$ ), 154.3 (1C, Ar-C), 116.3 (1C, Ar-C), 123.2 (1C, Ar-C), $168.5(1 \mathrm{C}, C \mathrm{C}), 33.2\left(1 \mathrm{C}, \mathrm{NHCOCH}_{2}\right), 118.6$ (1C, Indole- $C$ ), 119.6 (1C, Indole- $C$ ), 121.5 (1C, Indole- $C$ ), 111.3 (1C, Indole- $C$ ), 136.7 (1C, Indole- $C$ ), 127.3 ( $1 \mathrm{C}$, Indole- $C$ ), 109.7 (1C, Indole- $C$ ), 123.4 


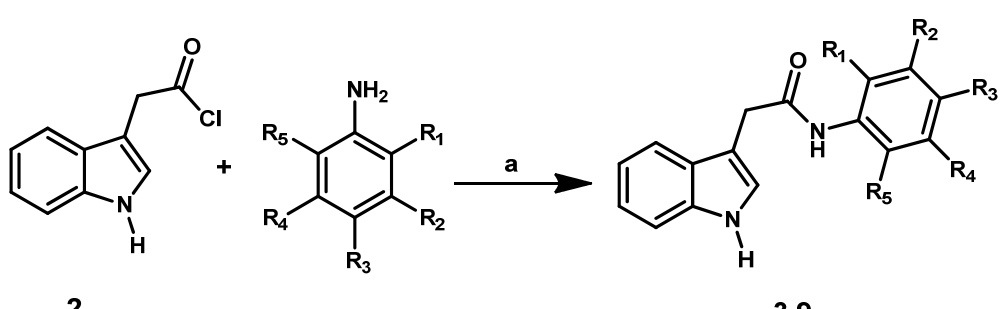

2

Reagents: (a) THF, anhydrous $\mathrm{K}_{2} \mathrm{CO}_{3}, \mathrm{~N}_{2}$ atmosphere, reflux.

\begin{tabular}{llllll}
\hline Compound & $\mathbf{R}_{\mathbf{1}}$ & $\mathbf{R}_{\mathbf{2}}$ & $\mathbf{R}_{\mathbf{3}}$ & $\mathbf{R}_{\mathbf{4}}$ & $\mathbf{R}_{\mathbf{5}}$ \\
\hline $\mathbf{3}$ & $\mathrm{H}$ & $\mathrm{H}$ & $\mathrm{H}$ & $\mathrm{H}$ & $\mathrm{H}$ \\
$\mathbf{4}$ & $\mathrm{OH}$ & $\mathrm{H}$ & $\mathrm{H}$ & $\mathrm{H}$ & $\mathrm{H}$ \\
$\mathbf{5}$ & $\mathrm{H}$ & $\mathrm{OH}$ & $\mathrm{H}$ & $\mathrm{H}$ & $\mathrm{H}$ \\
$\mathbf{6}$ & $\mathrm{H}$ & $\mathrm{H}$ & $\mathrm{OH}$ & $\mathrm{H}$ & $\mathrm{H}$ \\
$\mathbf{7}$ & $\mathrm{H}$ & $\mathrm{NO}_{2}$ & $\mathrm{OH}$ & $\mathrm{H}$ & $\mathrm{H}$ \\
$\mathbf{8}$ & $\mathrm{H}$ & $\mathrm{H}$ & $\mathrm{Br}$ & $\mathrm{H}$ & $\mathrm{H}$ \\
$\mathbf{9}$ & $\mathrm{H}$ & $\mathrm{OCH}_{3}$ & $\mathrm{OH}$ & $\mathrm{H}$ & $\mathrm{H}$ \\
\hline
\end{tabular}

Scheme 2

(1C, Indole-C). MS (EI, m/z(\%)): $266.14(\mathrm{M}+)$. Anal. Calcd. for $\mathrm{C}_{16} \mathrm{H}_{14} \mathrm{~N}_{2} \mathrm{O}_{2}$ : C, 72.16; H, 5.30; N, 10.52; 0, 12.02. Found: C, 72.14; H, 5.29; N, 10.51; 0, 12.00\%.

N-(hydroxy-3-nitrophenyl)-2-(1H-indol-3-yl)acetamide (7): Brown solid. Yield: $84 \%$. M.p.: 145-147 ${ }^{\circ} \mathrm{C}$. FT-IR $\left(\mathrm{KBr}, \mathrm{cm}^{-1}\right)$ : 3048-2828 (Ar-H), 3260 (NH of indole), 3200-3396 (phenolic $\mathrm{OH}), 1690(\mathrm{C}=0), 3198\left(\mathrm{NH}\right.$ of substituted aniline). ${ }^{1} \mathrm{H}$ NMR (400 MHz, $\left.\mathrm{CDCl}_{3}, \delta, \mathrm{ppm}\right)$ : 7.2-7.0 (m, 4H, Ar- $H$ ), 2.4-2.6 (d, $2 \mathrm{H}$, $\mathrm{CH}_{2}$ ) $, 4.5(\mathrm{~s}, 1 \mathrm{H}, \mathrm{N} H), 3.7$ (d, $1 \mathrm{H}$, indole $\mathrm{C} H$ ), $9.12(\mathrm{~s}, 1 \mathrm{H}, \mathrm{N}-\mathrm{H}$ ), $10.1(\mathrm{~s}, 1 \mathrm{H}$, phenolic $-\mathrm{OH}), 7.2-7.9(\mathrm{~m}, 3 \mathrm{H}, \mathrm{Ar}-\mathrm{H}$ of of substituted aniline). ${ }^{13} \mathrm{C}$ NMR (100 MHz, $\left.\mathrm{CDCl}_{3}, \delta, \mathrm{ppm}\right): 135.0$ (1C, $\mathrm{Ar}-\mathrm{C}$ ), 148.4 (1C, $\mathrm{Ar}-\mathrm{C}$ ), 119.8 (1C, $\mathrm{Ar}-\mathrm{C}$ ), 112.7 (1C, $\mathrm{Ar}-\mathrm{C}$ ), 132.4 (1C, $\mathrm{Ar}-\mathrm{C}$ ), 114.5(1C, $\mathrm{Ar}-\mathrm{C}$ ), 33.9 (1C, $\mathrm{NHCOCH}_{2}$ ), 118.5 (1C, IndoleC), 119.9 (1C, Indole- $C$ ), 121.5 (1C, Indole-C), 111.1 (1C, IndoleC), 136.7 (1C, Indole- $C$ ), 127.5 (1C, Indole- $C$ ), 109.2 (1C, IndoleC), 122.8 (1C, Indole-C). MS (EI, m/z(\%)): $311.01(\mathrm{M}+$ ). Anal. Calcd. for $\mathrm{C}_{16} \mathrm{H}_{13} \mathrm{~N}_{3} \mathrm{O}$ : C, 61.73; H, 4.21; N, 13.50; O, 20.56 . Found: C, 61.71; H, 4.20; N, 13.52; 0, 20.55\%.

$\mathrm{N}$-(4-bromophenyl)-2-(1H-indol-3-yl)acetamide (8): Brown semisolid. Yield: $89 \%$. FT-IR $\left(\mathrm{KBr}, \mathrm{cm}^{-1}\right)$ : 3049-2827 (Ar-H), $1670(\mathrm{C}=0), 3312$ (NH of indole), 3275 ( $\mathrm{NH}$ of substituted aniline). ${ }^{1} \mathrm{H}$ NMR ( $\left.400 \mathrm{MHz}, \mathrm{CDCl}_{3}, \delta, \mathrm{ppm}\right): 7.3-7.9(\mathrm{~m}, 4 \mathrm{H}, \mathrm{Ar}-$ $H$ ) 2.4-2.6 (d, $\left.2 \mathrm{H}, \mathrm{CH}_{2}\right), 4.7(\mathrm{~s}, 1 \mathrm{H}, \mathrm{NH}), 3.7(\mathrm{~d}, 1 \mathrm{H}$, indole $\mathrm{CH}$ ) 7.3-7.7 (m, 4H, Ar- $H$ of bromoaniline), $9.13(\mathrm{~s}, 1 \mathrm{H}, \mathrm{N}-\mathrm{H},)^{13} \mathrm{C}$ NMR (100 MHz, CDCl $, \delta, \mathrm{ppm}): 133.1$ (1C, Ar-C), 122.5 (1C, ArC), 114.1 (1C, Ar-C), 152.1(1C, Ar-C), 118.4 (1C, Ar-C), 122.5 (1C, $\mathrm{Ar}-\mathrm{C}$ ), 33.1 (1C, $\mathrm{NHCOCH}_{2}$ ), 168.9 (1C, CO), 118.8 (1C, Indole- $C$ ), 119.7 (1C, Indole-C), 121.9 (1C, Indole-C), 1110 (1C, Indole- $C$ ), 136.1 ( $1 \mathrm{C}$, Indole- $C$ ), 127.1 (1C, Indole- $C$ ), 109.1 (1C, Indole- $C$ ), 123.3 (1C, Indole-C). MS (EI, $\mathrm{m} / \mathrm{z}(\%)): 344.00(\mathrm{M}+)$. Anal. Calcd. for $\mathrm{C}_{16} \mathrm{H}_{13} \mathrm{BrN}_{2} \mathrm{O}: \mathrm{C}, 58.38 ; \mathrm{H}, 3.98 ; \mathrm{Br}, 24.27$; N, 8.51; 0, 4.86. Found: C, 58.36; H, 3.99; Br, 24.25; N, 8.50; 0, $4.85 \%$.

N-(4-hydroxy-3-methoxyphenyl)-2-(1H-indol-3-yl)acetamide (9): Brown semisolid. Yield: 87\%. FT-IR $\left(\mathrm{KBr}, \mathrm{cm}^{-1}\right)$ : 3039-2817 (Ar-H), 1699 (C=0), 3310 ( $\mathrm{NH}$ of indole), 3210-3300 (phenolic $\mathrm{OH}), 3297$ (NH of substituted aniline). ${ }^{1} \mathrm{H}$ NMR $(400 \mathrm{MHz}$, $\mathrm{CDCl}_{3}, \delta, \mathrm{ppm}$ ): 7.4-7.1 (m, 4H, Ar- $\left.\mathrm{H}\right), 2.2-2.6\left(\mathrm{~d}, 2 \mathrm{H}, \mathrm{CH}_{2}\right), 4.4(\mathrm{~s}$, $1 \mathrm{H}, \mathrm{N} H), 3.9(\mathrm{~d}, 1 \mathrm{H}$, indole $\mathrm{CH}) 9.4(\mathrm{~s}, 1 \mathrm{H}, \mathrm{N}-H), 11.2(\mathrm{~s}, 1 \mathrm{H}$, phenolic $-\mathrm{OH}$ ), $3.8\left(\mathrm{~s} .3 \mathrm{H}, \mathrm{OCH}_{3}\right)$,6.8-7.2 (m, 3H, Ar-H of substituted aniline). ${ }^{13} \mathrm{C}$ NMR (100 $\left.\mathrm{MHz}, \mathrm{CDCl}_{3}, \delta, \mathrm{ppm}\right): 56.0$ (1C, $\left.\mathrm{ArOHOCH}_{3}\right), 151.4(1 \mathrm{C}, \mathrm{Ar}-\mathrm{C}$ ), 144.5 (1C, $\mathrm{Ar}-\mathrm{C}$ ), 117.5 (1C, Ar- C), 115.8 (1C, Ar-C), 132.5 (1C, $\mathrm{ArC}$ ), 106.2 (1C, $\mathrm{ArC}$ ), 33.7 (1C, $\mathrm{NHCOCH}_{2}$ ), 118.6 (1C, Indole- $C$ ), 119.3 (1C, Indole-C), 121.2 (1C, Indole- $C$ ), 111.0 (1C, Indole- $C$ ), 136.5 (1C, Indole- $C$ ),
127.3 (1C, Indole- $C$ ), 109.0 (1C, Indole- $C$ ), 123.0 (1C, Indole- $C$ ). MS (EI, m/z(\%): $296.22\left(\mathrm{M}+\right.$ ). Anal. Calcd. for $\mathrm{C}_{17} \mathrm{H}_{16} \mathrm{~N}_{2} \mathrm{O}_{3}$ : C, 68.91; H, 5.44; N, 9.45; 0, 16.20. Found: C, 68.90; H, 5.45; N, 9.46; $0,16.18 \%$.

\subsection{Biological evaluation - antioxidant activity studies}

The newly synthesized compounds were screened for their antioxidant activities using a stable free radical DPPH assay and Inhibition of microsomal LPO assay. The compounds under study were dissolved in distilled ethanol $(50 \mathrm{~mL})$ to prepare $1000 \mu \mathrm{M}$ solution. Solutions of different concentrations $(10,25$, $50,100,200$ and $500 \mu \mathrm{M}$ ) were prepared by serial dilution and the antioxidant activity was studied.

\subsubsection{Animals}

The antioxidant activity of the target compounds 1-9 and BHA was tested on adult male Wister rats weighing 450-520 g. All animals were allowed free access to water and kept at constant diet. Totally 10 rats were used for the isolation of microsomes.

\subsubsection{DPPH free radical scavenging activity}

The DPPH radical scavenging effect was carried out according to the method first employed by Blois [24]. Compounds of different concentrations were prepared in distilled ethanol, $1 \mathrm{~mL}$ of each compound solutions having different concentrations $(10,25,50,100,200$ and $500 \mu \mathrm{M})$ were taken in different tubes, $4 \mathrm{~mL}$ of $0.1 \mathrm{mM}$ ethanol solution of DPPH was added and shaken vigorously. The tubes were then incubated in the dark room at room temperature (RT) for 20 min. A DPPH blank was prepared without compound, and ethanol was used for the baseline correction. Changes (decreases) in the absorbance at $517 \mathrm{~nm}$ were measured using a UV-Visible Spectrophotometer and the remaining DPPH was calculated. The percent decrease in the absorbance was recorded for each concentration, and percent quenching of DPPH was calculated on the basis of decrease in absorbance of the radical. The radical scavenging activity was expressed as the inhibition percentage and was calculated using the formula;

Radical scavenging activity $(\%)=\left[\left(A_{0}-A_{1} / A_{0}\right) \times 100\right]$ 
where $A_{o}$ is the absorbance of the control (blank, without compound) and $A_{1}$ is the absorbance of the compound. The radical scavenging activity of BHA was also measured and compared with that of the newly synthesized compound.

\subsubsection{Inhibition of microsomal lipid peroxidation assay}

Liver excised from adult male Wister rats, was homogenized $(20 \mathrm{~g} / 100 \mathrm{~mL}$ Tris buffer $)$ in $0.02 \mathrm{~mol} / \mathrm{L}$, tris buffer $(\mathrm{pH}=7.4)$. Microsomes were isolated by the calcium aggregation method [25]. $100 \mu \mathrm{L}$ of liver microsomal suspension ( $0.5 \mathrm{mg}$ protein) was incubated with $1 \mathrm{mmol} / \mathrm{L}$ each of $\mathrm{FeSO}_{4}$ and ascorbic acid with or with out compounds in a total volume of $1 \mathrm{~mL}$ in $0.1 \mathrm{~mol} / \mathrm{L}$ phosphate buffer $(\mathrm{pH}=$ 7.4). After incubation at $37^{\circ} \mathrm{C}$ for $60 \mathrm{~min}$, the reaction mixture was boiled with TBA $(0.67 \mathrm{~g} / 100 \mathrm{~mL}$ water) for $15 \mathrm{~min}$. Formation of TBA reactive substances (TBARS) was calculated from the absorbance at $535 \mathrm{~nm}$ [26]. BHA was used as the positive control.

\subsubsection{Statistical analysis}

Tests were carried out in triplicate for 3-5 separate experiments. The amount of compound needed to inhibit DPPH free radicals and Lipid peroxyl radical concentration by $50 \%$, $\mathrm{IC}_{50}$, was graphically estimated using a linear regression algorithm.

\section{Results and discussion}

\subsection{Chemistry}

Indole-3-acetic acid was synthesized by applying known method [27] (Scheme 1). The active site for the coupling of aniline and substituted anilines to the basic moiety was sparce, thus we carried out the conversion of acid-to-acid chloride reaction in order to obtain key intermediate in which, the coupling of aniline and substituted anilines could be done very easily with simple experiment protocol along with good yield. The synthesis of Indole-3-acetic acid analogues conjugated with aniline and substituted anilines were realized in two steps. First step, the key intermediate $2(1 H$-indole-3-yl acetyl chloride (2) was prepared in good yield by conversion of acid to acid chloride in the presence of thionyl chloride (Scheme 1). In the second step, further coupling of respective aniline and substituted anilines to the key intermediate by base condensation reaction to obtain the novel Indole-3-acetic acid analogues 3-9 (Scheme 2).

In the present investigation, in order to study the antioxidant properties of 2-(1H-indole-3-yl) acetic acid (1) and its derivatives 2-9, we have synthesized array of Indole-3acetic acid derivatives conjugated with aniline and substituted anilines. In order to couple aniline and substituted anilines, the model compound 2-(1H- indole-3-yl) acetic acid (1) is converted to $2(1 H$-indole-3-yl) acetyl chloride (2) in the presence of thionyl chloride. Procedure for synthesis is outlined in Scheme 1.

2(1H-indole-3-yl)acetyl chloride (2) was identified through thin layer chromatography technique by using methanol: chloroform (20:80) as eluent. The excess thionyl chloride was removed under high vaccum. The synthesized compounds were characterized by various physico-chemical and spectroscopic techniques like IR, ${ }^{1} \mathrm{H}$ NMR, ${ }^{13} \mathrm{C}$ NMR, mass, and elemental analysis. IR spectrum of 2-(1H-indol-3-yl) acetyl chloride (2) reveals the presence of carbonyl stretching at $1700 \mathrm{~cm}^{-1}$, absence of $-\mathrm{OH}$ stretching at $3739 \mathrm{~cm}^{-1}$ confirm the conversion of acid to acid chloride. The structure of compound $\mathbf{2}$ was further confirmed by ${ }^{1} \mathrm{H}$ NMR studies, here the absence of signal at $9.7 \mathrm{ppm}$ which corresponds to carboxylic $-\mathrm{OH}$ proton confirms the expected acid chloride product. 2 ( $1 \mathrm{H}$-indole-3yl)acetyl chloride (2) conjugated with aniline and substituted anilines were synthesized and the protocol for the synthesis is outlined in Scheme 2.

We have carried out the base condensation reaction at inert atmosphere $\left(\mathrm{N}_{2}\right)$ with good yield (76-89\%). The newly synthesized compounds were purified by column chromatography using silica gel 60-120 mesh and ethyl acetate:hexane $(60: 40)$ as eluent. Coupling of aniline and substituted anilines was done by base condensation reaction using anhydrous $\mathrm{K}_{2} \mathrm{CO}_{3}$ as base. The IR spectra of all the substituted aniline analogues showed two sharp N-H band i.e., amide and indole $(\mathrm{N}-\mathrm{H})$ band at around $3198-3389 \mathrm{~cm}^{-1}$ and also reveal the presence of aromatic peaks $(\mathrm{Ar}-\mathrm{H})$ at the respective region 2598-3124 $\mathrm{cm}^{-1} . \mathrm{CH}_{2}$ stretching band was observed at 2971-3026 cm-1. ${ }^{1} \mathrm{H}$ NMR spectra of all conjugated analogues 3-9 showed $\mathrm{N}-\mathrm{H}$ protons as singlet at 4.0-9.9 ppm. The signal due to phenolic $-\mathrm{OH}$ in all the analogues appeared as singlet at about 9.7-11.2 ppm. In addition to phenolic - $\mathrm{OH}$, $\mathrm{OCH}_{3}$ protons present in the compound 9 resonated as singlet at $3.8 \mathrm{ppm}$, other aromatic protons were observed at expected regions (6.7-7.9 ppm). All the analogues showed mass according to their $\mathrm{M}^{+}$ions.

\subsection{Antioxidant activities}

In order to establish some structure-activity relationship based on position and presence of different substituents and to understand how it affects the antioxidant activity, present research was taken. The evaluation of the antioxidant effects of the newly synthesized compounds having different concentrations were examined by two well documented in vitro assays like DPPH free radical scavenging assay and Inhibition of microsomal lipid peroxidation (LPO) assay.

Antioxidants react with DPPH, which is a stable free radical and convert it to 2,2-diphenyl-1-picryl hydrazine. The degree of discoloration indicates the scavenging potentials of the compounds. The percentage (\%) DPPH activities of all the newly synthesized compounds were showed in the Figure 1.

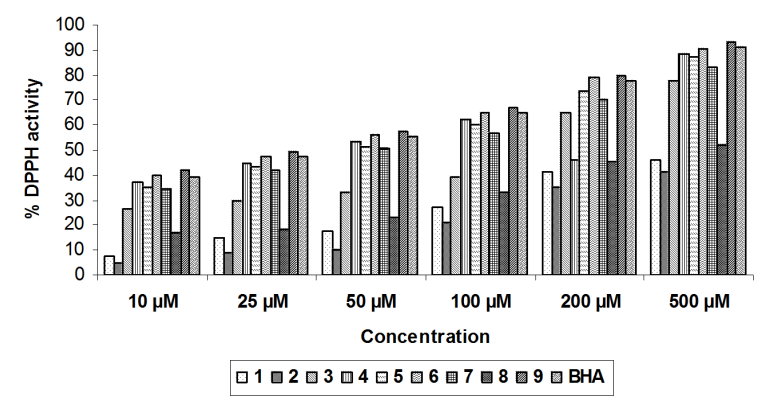

Figure 1. \% DPPH radical scavenging activity of indole-3-acetic acid and its analogues. Each value represents the mean $\pm \operatorname{SD}(n=3)$.

From the Figure 1, compound $\mathbf{1}$ and $\mathbf{2}$ showed considerable activities and this may be due to the presence of indole $\mathrm{N}-\mathrm{H}$ moiety. Further coupling of aniline and substituted anilines gave the significant changes in the activity. Among them, the compound 9 bearing methoxy group (electron donating group) addition to phenolic moiety increased the stability of the radical and hence the antioxidant activity [23]. Thus, the introduction of a methoxy group increases the hydrogen donation ability and therefore showed dominant DPPH activity compare to BHA an internal standard. All the analogues demonstrated significant radical scavenging effect in concentration dependent manner. On the other hand, the half inhibition concentration $\left(\mathrm{IC}_{50}\right)$ for all the newly synthesized analogues including the reference antioxidant BHA was calculated graphically using a linear regression algorithm and shown in Table 1. 
The presence of nitro group (electron with drawing group) in compound $\mathbf{7}$ exhibits slightly less activity to that of $\mathbf{9}$. Compounds 4-6 showed comparable, but slightly less activity to the standard BHA. The increasing order of DPPH activity of newly synthesized analogues is as follows $9>$ BHA $>6>7>4>$ $5>8>3>1>2$.

From LPO studies, as shown in Figure 2, among the synthesized compounds 1, 2, and $\mathbf{3}$ inhibits lipid peroxidation moderately and showed considerable activities. Compound $\mathbf{4}$, 5, 6, 7 and 8 and inhibits fairly the peroxyl radicals generated in the system showed good activities. Whereas, compound $\mathbf{9}$ bearing methoxy group (electron donating group) additions to phenolic moiety demonstrate dominant on inhibiting LPO of liver microsomes.

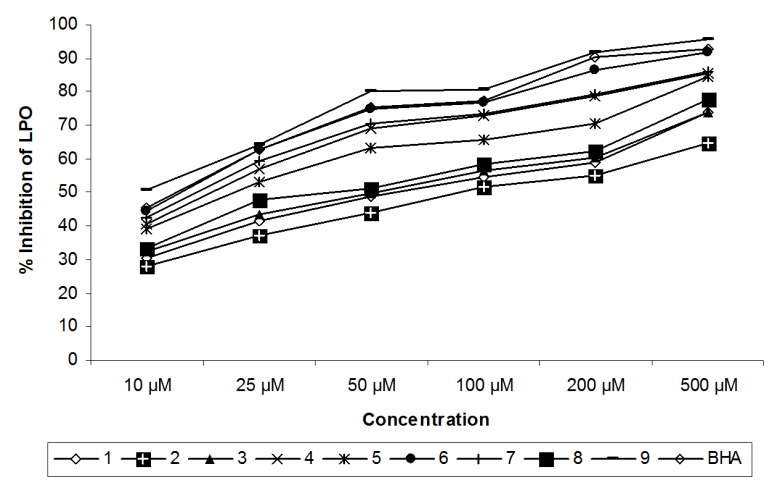

Figure 2. \% Inhibition of microsomal LPO by indole-3-acetic acid and newly synthesized analogues. Each value represents the mean $\pm S D(n=3)$.

IC50 values of LPO inhibition for the newly synthesized analogues were depicted in Table 1 . LPO has been broadly defined as the oxidative deterioration of polyunsaturated lipids [28]. Initiation of a peroxidation sequence in a membrane or polyunsaturated fatty acid is due to abstraction of a hydrogen atom from the double bond in the fatty acid. The free radical tends to stabilize by a molecular rearrangement to produce a conjugated diene, which then readily reacts with oxygen molecule to give a peroxy radical [29]. Peroxy radicals can abstract a hydrogen atom from another molecule to give lipid hydroperoxide, $\mathrm{R}-\mathrm{OOH}$. A probable alternative fate of peroxy radicals is to form cyclic endoperoxides fragment to aldehydes such as malondialdehyde (MDA) and polymerization products. MDA and 4-hydroxy nonenal are the major break down products of LPO. MDA is usually taken as a marker of LPO and oxidative stress [30]. All the synthesized compounds exhibit same order of activity in both the assay performed.

Table 1. 50\% Inhibition of DPPH radical and Microsomal LPO inhibition by indole-3-acetic acid and its analogues each value represents mean \pm SD $(n=3)$

\begin{tabular}{l|ll}
\hline Compounds & $\begin{array}{l}\text { DPPH activity } \mathbf{I C}_{\mathbf{5 0}} \\
(\boldsymbol{\mu} \mathbf{M} / \mathbf{m L})\end{array}$ & $\begin{array}{l}\text { Microsomal LPO inhibition IC } \mathbf{I}_{50} \\
(\boldsymbol{\mu} \mathbf{M} / \mathbf{m L})\end{array}$ \\
\hline 1 & $75 \pm 0.1$ & $80 \pm 0.7$ \\
2 & $79 \pm 0.3$ & $85 \pm 0.4$ \\
3 & $72 \pm 0.7$ & $70 \pm 0.3$ \\
4 & $18 \pm 0.9$ & $16 \pm 0.8$ \\
5 & $19 \pm 0.5$ & $18 \pm 0.1$ \\
6 & $14 \pm 0.3$ & $12 \pm 0.3$ \\
7 & $17 \pm 0.1$ & $14 \pm 0.5$ \\
8 & $21 \pm 0.8$ & $20 \pm 0.9$ \\
9 & $10 \pm 0.5$ & $7 \pm 0.1$ \\
BHA & $12 \pm 0.7$ & $10 \pm 0.1$ \\
\hline
\end{tabular}

\section{Conclusion}

Synthesis and antioxidant properties of indole-3-acetic acid and its derivatives have been investigated. Indole-3-acetic acid conjugated with aniline and substituted anilines were prepared by base condensation reaction in moderate to high yield. A key intermediate, 2-(1H-indol-3-yl)acetyl chloride (2) was prepared by conversion of indole-3-acetic acid to acid chloride. The antioxidant properties of new analogues were evaluated by DPPH free radical scavenging activity and LPO inhibition assay. In both the assays, initially 2-(1H-indol-3-yl)acetyl chloride (2) showed considerable activity. Further coupling of aniline and substituted anilines to 2-(1H-indol-3-yl)acetyl chloride (3-9) enhance the antioxidant properties. Coupling of methoxy substituted i.e compound 9 revealed high antioxidant activity which was more than the standard (BHA). It is conceivable from these studies that the coupling of aniline and substituted anilines is the most important feature for the significant antioxidant activity of indole-3-acetic acid analogues studied. Our investigation may be use full in the treatment of pathologies in which free radical oxidation plays a fundamental role.

\section{Acknowledgement}

Authors are also thankful to the Indian Institute of Science, Bangalore for providing the spectral data.

\section{References}

[1]. Babior, B. M. Am. J. Med. 2000, 109, 33-44.

[2]. Lander, H. M. FASEB J. 1997, 11, 118-124

[3]. Gibson, G. E. Free Radical Biol. Med. 2002, 32, 1061-1070.

[4]. Giasson, B. I.; Ischiropoulos, H.; Lee, V. M. Y.; Trojanowski, J. Q. Free Radical Biol. Med. 2002, 32, 1264-1275.

[5]. Jang, M.; Cai, L.; Udeani, G. O.; Slowing, K. V.; Thomas, C. F.; Beecher, C. W. W.; Fong, H. H. S.; Farnsworthm, N. R.; Kinghorn, A. D.; Mehta, R. G.; Moon, R. C.; Pezzuto, J. M. Science 1997, 275, 218-220.

[6]. Heinecke, J. W. Free. Radic. Biol. Med. 2002, 32, 1090-1101.

[7]. Hazell, L. J.; Baernthaler, G.; Stocker, R. Free Radical Biol. Med. 2001 31, 1254-1262.

[8]. Cuzzocrea, S.; Riley, D. P.; Caputi, A. P.; Salvemini, D. Pharm. Rev. 2001 53, 135-159.

[9]. Saija, A.; Scalese, M.; Lanza, M.; Marzullo, D.; Bonina, F.; Castelli, F. Free Rad. Biol. Med. 1995, 19, 481-486.

[10]. Bors, W. H.; Michel, C.; Saran, M. Methods Enzymol. 1990, 186, 343 355.

[11]. You-Zhi, T.; Zai-Qun, L. Bioorg. Med. Chem. 2007, 15, 1903-1913.

[12]. Lucarini, M.; Pedrielli, P.; Pedulli, G. F.; Valgimigli, L.; Gigmes, D.; Toroda, P. J. Am. Chem. Soc. 1999, 121, 11546-11533.

[13]. Vinson, J. A.; Dabbagh, Y. A.; Serry, M. M.; Jang, J. J Agric. Food Chem. 1995, 43, 2800-2802.

[14]. Salopek-sondi, B.; Piljac-Zegarac, J.; Magnus, V.; Kopjar, N. J. Biochem. Mole Toxi. 2010, 24, 165-173.

[15]. Olgen, S.; Kilic, Z.; Ada, A. O.; Coban, T. Arch. Pharm. Chem. Life. Sci. 2007, 340, 140-146.

[16]. Gerard, A. P.; Maria A. P.; Mario, S.; Giuseppe, P. Il Farmaco 1998, 53, 161-168.

[17]. Andrey, E. S.; Alexander, A. S.; Yuri, N. L.; Tatyana, V. B.; Vladimir, N. B.; Maria, N. P. Bioorg. Med. Chem. 2005, 13, 2285-2291.

[18]. Alicia, J.; Néstor E.; Massa ; Leonor, L.T.; Nora B. O. Vibr. Spect. 2000 537, 161-178.

[19]. Keith, J. C.; Malcolm, H.T. R. Euro. J. Pharm. 1974, 29, 154-160.

[20]. Ali, S.; Veena, U.; Edward, G. C.; Mirlinda, B.; Dalian, Z.; Jean-Francois, M.; Kevin, R. C.; Michel, J.; Anthony, O. K.; Rob, D. L.; Edward. J. J. G.; Ralph, P. V.; Richard, D. T. Tetrahedron Asym. 2005, 16, 3094-3098.

[21]. Vijay, K. H.; Gnanendra, C. R.; Channe, G. D.; Naik, N. E. J. Chem. 2008, 5), 1123-1132.

[22]. Vijay, K. H.; Kishor, K. C.; Naik, N. Med. Chem. Res. 2011, 20, 101-108.

[23]. Vijay, K. H.; Nagaraja, N. Eur. J. Med. Chem. 2010, 45(1), 2-10.

[24]. Blois, M. S. Nature 1958, 181, 1199-1199.

[25]. Kamath, S. A.; Ryubin, E. Biochem. Biophys. Res. Comm. 1972, 49, 5259.

[26]. Buege, J. A.; Aust, S. T. Methods Enzymol. 1978, 52, 302-310.

[27]. Herbert, J. E.; Donald, G. C. Org. Synth. Coll. 1973, 5, 654-654.

[28]. Kappus, H. Lipid peroxidation-Mechnism and biological relevance. Taylor \& Francis, 1991.

[29]. Jadhav, S. J.; Nimbalkar, S. S.; Kulkarani, A. D.; Madhavi, D. L. Lipid oxidation in biological and food systems. In: Madhavi, D. L.; Deshpande, S. S.; D. K. Salunke (Eds), Food antioxidants. New York: Marcel Dekker, 1996.

[30]. Janero, D. Free Rad. Bio. Med. 1990, 9, 515-540. 